\title{
Relationship between Family Functioning and Academic Engagement of Secondary School Students: The Moderating Role of Resilience
}

\author{
Emily O. Adeniji ${ }^{1}$, Yomi Akindele-Oscar ${ }^{2}$, Sesan O. Mabekoje ${ }^{2}$ \\ Federal College of Education ${ }^{1}$, Olabisi Onabanjo University ${ }^{2}$ \\ Nigeria
}

\begin{abstract}
This study investigated the moderating role of resilience in the relationship between family functioning and academic engagement among secondary school students in Ogun State, Nigeria. The descriptive survey research design was adopted. A sample of 1800 senior secondary school students selected through multi-stage random sampling technique participated in the study. Three instruments; Family Assessment Device (FAD), Utrecht Work Engagement Scale - Student and Connor-David Resilience Scale were used for data collection. Data analysis employed the use of Multiple Regression Analysis. Results revealed that Resilience predicted academic engagement $($ Coeff $=$ .459; $S E=.028 ; t=16.488 ; p<.05)$. Family functioning predicted academic engagement (Coeff $=.049 ; S E=.020 ; t=2.431 ; p<.05)$. However, resilience inversely interacted with family functioning (Coeff $=-.002 ; S E=.001 ; t=-1.971 ; p$ $<.05)$ to predict academic engagement. It was concluded that the relationship between family functioning and academic engagement will be inversely moderated by resilience.
\end{abstract}

\section{Introduction}

The concept of academic engagement has received great attention in both theoretical and empirical literature [1 - 4]. Academic engagement is the totality of what makes an individual a student with behaviour uniquely fulfilling the identity nature of being a student. This is said to be of three components vis-à-vis behavioural, emotional and cognitive. All these three components are logically linked together in producing overall school success.

Academic engagement was found to be positively related to class collective efficacy [4] and all measures of achievement [5]. It was found to be negatively associated with teachers' emotional obstruction [6], shyness [5] and externalizing behavior [4, 7]. Student's academic engagement is influenced by basic psychological needs [8]. It has also been established that emotional creativity predicts intrinsic motivation and academic engagement of university students by the experience of positive emotions [9]. Students adopted more of problem- focused coping than emotion-focused coping strategies and were academically engaged [10]. The more a person has psychological capitals, particularly optimism and hope, the more he/she would have academic engagement, with increased behavioral engagement as a main [11]. Higher disciplinary structure was associated with higher engagement, and higher student support was associated with higher engagement and grades [12]. However, evidence of the prediction of academic engagement by family functioning is sparse and not well investigated.

Family functioning is defined as the way in which the family members interact, react to, and treat other family members; it includes variables within the family such as communication styles, traditions, clear roles and boundaries, and the degree of fusion, flexibility, adaptation and resilience [13]. Family is a strong communicative base of adolescent development, even though environment has its own influence as well [14]. There was a significant correlation between the dimensions of family functioning and areas of self-esteem; except for lack of independence, and public, academic, and physical self-esteem [15]. Adolescents' reports of increased family functioning predicted decreased externalizing problems, as well as increased levels of familism and global self-worth [16]. There is a significant correlation between family function (except lack of independence) and students' academic achievement [17]. Adolescents with high or increasing family conflict trajectories, and low or decreasing family support trajectories, were at relatively greater risk of sexual risk behaviors and sexually transmitted infection [18]. Higher levels of adolescent family functioning were associated with less health risk behaviors and depressive symptoms [19].

The functioning of a family is a significant factor in the context of tobacco, alcohol, and drug use [14]. When a family experiences stress, an adverse event, a traumatic event, or a life change (positive or negative), the family enters a period of adjustment. The majority of family functioning models have evolved from a systems theory, which conceptualizes family as a type of "ecosystem" made up of many interdependent parts. As such, family functioning models emphasize the interconnected of each element within the family system, and posit that to fully understand an individual operating in a family, 
it is necessary to see how the entire unit functions. Family functioning has been shown to relate significantly negatively with Adolescent Health Risk Behaviors and Depressive (HRB/DS0 [19]. Family functioning is among the most important factors ensuring the mental health of family members. Disorder or disturbance in family functioning would cause many psychological problems for family members [20]. Almost 17 percent of quality of life variance among addicts could be explained by dimensions of family functioning namely: roles and communication [21]. A significant relationship between family functioning score and total aggression score [22].

Secondary school adolescents develop successfully against odds; this is in line with resilience. Resilience is an everyday general term meaning elasticity and stretch, which refers to the ability to recoil or spring back into shape, after bending, stretching or being compressed [23] and is enabled by internal, individual assets as well as the resources available in a person's environment to support healthy development [24]. For humans, this term refers to the ability to withstand or recover quickly from difficult conditions. Resilience is broadly defined as the ability to respond adaptively to challenges or adversity [25]. It is the individual attributes that are related to the process of successfully adapting to the environment in the face of adverse conditions [26].

It is the ability to reduce the chances of a shock, to absorb a shock if it occurs (abrupt education of performance) and recover quickly after a shock (reestablish normal performance) [27]. The conceptualization of resilience as a trait shows the characteristic that a person has, that allows success in the face of adversity [28-30].

Resilience has been found to be re correlated with negative symptoms, defeatist beliefs, depression/anxiety symptoms, and social cognition [25]. There were no significant correlations with nonsocial cognition or psychotic symptoms. Resilience was correlated with community functioning in the domains of work, independent living, and social and family relationships. The relationship between resilience and Post Traumatic Growth was curvilinear: The highest levels of PTG occurred when resilience levels were moderate [31]. PostTraumatic Growth (PTG) and resilience are positively related [32]. Resilience was negatively related to distress but positively related to psychological well-being [33] to mention a few.

The relationship between adverse experiences and later development has been explored by many researchers, leading to the conceptualization of resilience as a factor explaining the normal or optimal development of some individuals exposed to adversity [34]. Perceived stressful life events could also affect school adjustment through the mediation of resilience [35]. Emotion regulation ability is a significant predictor of adolescents' resilience [36].

Resilience has been found to moderate the associations between parental problem drinking and adolescents' internalizing and externalizing behaviors of Korean adolescents [37], hassles and psychological distress [38], emotional intelligence and clinical communication ability among Chinese practice nursing students [39], exposure to violence and Posttraumatic Reexperiencing in Mi'kmaq Youth [40], ostracism and depression among Chinese adolescents [41], academic burnout and the perception of psychological health in nursing students [42], perceived stress and binge eating symptoms among young adult women [43], longitudinal linkage between adolescent Posttraumatic Stress Disorder Symptoms and Posttraumatic Growth [44] and Posttraumatic Growth and adolescent academic burnout in a postdisaster context [45].

However, the moderating effect of resilience between family functioning and academic engagement has not been established. Generally, from the trend and direction of the literature, it has been established that for the secondary school adolescents to have a wholesome academic engagement, they should be able to adjust positively to different emotional provoking situations arising from schools and families; all these demand their resiliency level.

It was therefore hypothesized that resilience would moderate the relationship between family functioning and academic engagement of secondary school students.

\section{Method}

\subsection{Design}

This study adopted a descriptive survey research design of the expost facto type. The communication mode of data collection for the present study is survey. The object of a survey is to provide a quantitative or numeric description of some fraction of a population (a sample) by asking relevant questions that address some unknown aspect of the population [46].

The topical scope of this study is statistical rather than a case study. The research environment is the field rather than the laboratory as could be in the experimental research. The time dimension is cross sectional since data are to be collected at the same time and not over a long period of time as is in the case of the longitudinal studies. The nature of the relationship between the variables is descriptive. Conceptually therefore, the study is an expost facto, survey, descriptive, cross- sectional, field, and statistical study. 
Dependent variable of the study was academic engagement. The independent variable was family functioning while the moderating variable of the study was resilience.

\subsection{Participants}

A sample size of 1,800 Senior Secondary School students was used for this study. This was selected through the multistage stratified random sampling technique. The first stage of selection was the selection of three local Government Areas from each of the three Senatorial Districts. A list of all the Local Government areas in the Senatorial Districts was made from which three local government areas were selected randomly from each of the Senatorial District.

Thereafter, five senior secondary schools were randomly selected through simple random sampling technique from each of the selected local government areas. Finally, forty senior secondary school; twenty each from SSI and SSII students were randomly selected from each of the forty-five schools were sampled, amounting to one thousand and eight hundred senior secondary school students I and II for this study. The choice of SSI and SSII was because cases of school dropout, inferiority complex, bad peer influence and many more are predominant among them.

\subsection{Instruments}

2.3.1. Utrecht Work Engagement Scale-Student (UWES-S). Academic engagement was assessed using the UWES-S, a modified version of the UWES [47] which was adapted for use in student samples. The UWES-S is a 14 item scale that is made up of three subscales, namely; vigour (5 items: e.g. "When I am studying, I feel mentally strong. "), dedication (5 items: e.g. "I find my studies to be full of meaning and purpose") and absorption (4 items: e.g. "Time flies when I am studying."). The scale has a seven point frequency rating scale ranging from $1=$ strongly disagreed to $7=$ strongly agree. Cronbach alpha coefficients of 0.68 and $0.80 ; 0.91$ and; 0.73 and 0.75 have been reported for vigour, dedication, and absorption respectively [48].

2.3.2. The Family Assessment Device (FAD). Family functioning was measured using The Family Assessment Device (FAD) - a self-report screening instrument that assesses family functioning [49]. FAD is based on the McMaster Model of Family Functioning (MMFF) which described the characteristics and structural organisation of families to differentiate between healthy and unhealthy patterns. FAD consists of 60 items rated on a 4-point Likert scale, from "Strongly agree" to "Strongly disagree". This instrument consists of seven scales; six dimensions of family functioning identified by MMFF and a General Functioning scale. The six scales are: Problem Solving (e.g. We usually act on our decisions regarding problems.), Communication (e.g. You can't tell how a person is feeling from what they are saying), Roles (e.g. When you ask someone to do something, you have to check that they did it.), Affective Responsiveness (e.g. We are reluctant to show our affection for one another.), Affective Involvement (e.g. If someone is in trouble, the others become too involved), and Behaviour Control (e.g. You can easily get away with breaking the rules) and general functioning (e.g. In times of crisis we can turn to each other for support).

The FAD has a high levels of consistency across different types of families, acceptable levels of testretest reliability, low correlations with social desirability, moderate correlations with other selfreport measures of family functioning, and differentiates significantly between clinician-rated healthy and unhealthy families 6 of 7 scales have reported internal reliability above. 70

2.3.3. Connor-Davidson Resilience Scale. Resilience was assessed using the Connor Davidson Resilience Scale CD - RISC originally developed to collect data on student's level of resiliency [50]. The CD-RISC comprised of 25 questions. The respondents were asked to answer in terms of how they have felt within the last month. Each question will be rated on a 5-point Likert-style scale, ranging from not true at all (0) to true nearby all the time (4). Cronbach alpha values of between 0.79 and 0.88 have been reported for the scale [50]

\subsection{Procedure}

The three instruments were administered on the participants in their various schools. Students sampled in each school were seated in a classroom and assured of the confidentiality of information provided in the instruments. The filled-out questionnaires were collected the same day they were completed. Data collected were analysed using both descriptive statistics of means and standard deviation to provide the description of data. Moderation Analysis was done using the Conditional Process Analysis macro [51]. Results were tested at .05 level of significance. 


\section{Results}

\subsection{Preliminary results}

Results in Table 1 indicated that academic engagement, family functioning and resilience are variously positively related. Academic engagement is significantly related to family functioning $(r=$
$.251 ; p<.01)$ and resilience $(\mathrm{r}=.438 ; p<.01)$. Family functioning is also related to resilience $(\mathrm{r}=$ $.490 ; p<.01)$.

Table 1. Descriptive Statistics and Correlations Indices for the Study Variables

\begin{tabular}{lrrr}
\hline & Academic Engagement & Family Functioning & Resilience \\
\hline Academic Engagement & 1 & $.251^{* *}$ & $.438^{* * *}$ \\
Family Functioning & & 1 & $.490^{* *}$ \\
Resilience & & & 1 \\
Min. & & & \\
Max. & 61.711 & 136.137 & 71.642 \\
Mean & 13.539 & 17.020 & 11.994 \\
Std. Dev. & & & \\
Skewness & & \\
Kurtosis & & & \\
$* *$. Correlation is significant at the 0.01 level (2-tailed). &
\end{tabular}

\subsection{Moderation analysis}

Table 2. Coefficients for the moderating role of resilience between family functioning and academic engagement

\begin{tabular}{lrrrrrr}
\hline & \multicolumn{6}{c}{ Consequence (Academic Engagement) } \\
\cline { 2 - 7 } Antecedents & Coeff & \multicolumn{1}{c}{$\mathrm{SE}$} & $\mathrm{t}$ & $\mathrm{p}$ & \multicolumn{1}{c}{ LLCI } & ULCI \\
\hline Constant & 61.923 & .306 & 202.354 & .000 & 61.323 & 62.523 \\
Resilience & .459 & .028 & 16.488 & .000 & .404 & .514 \\
Family Functioning & .049 & .020 & 2.431 & .015 & .009 & .088 \\
Resilience X Family Functioning & -.002 & .001 & -1.971 & .049 & -.004 & .000 \\
Model Summary & \multicolumn{7}{c}{$\mathrm{R}=.442 ; \mathrm{R}^{2}=.196 ; \mathrm{F}(3,1796)=145.620 ; p=.000$} & \\
\hline
\end{tabular}

Results in Table 2 revealed that resilience predicted academic engagement (Coeff $=.459 ; \mathrm{SE}=$ $.028 ; \mathrm{t}=16.488 ; p<.05)$. Family functioning also predicted academic engagement $($ Coeff $=.05 ; \mathrm{SE}=$
$.020 ; \mathrm{t}=2.431 ; p<.05)$. However, resilience interacted inversely with family functioning (Coeff $=$ $-.002 ; \mathrm{SE}=.001 ; \mathrm{t}=-1.971 ; p=.05)$ to predict academic engagement.

Table 3. Conditional effect of Family Functioning on Academic Engagement at values of Resilience

\begin{tabular}{rrrrrrr}
\hline Resilience & Effect & SE & $\mathrm{t}$ & $\mathrm{p}$ & LLCI & ULCI \\
\hline-11.994 & .074 & .027 & 2.774 & .006 & .022 & .127 \\
.000 & .049 & .020 & 2.431 & .015 & .009 & .088 \\
11.994 & .023 & .021 & 1.138 & .255 & -.017 & .064 \\
\hline
\end{tabular}

Values for quantitative moderators are the mean and plus/minus one SD from mean.

Values for dichotomous moderators are the two values of the moderator.

Results in Table 3 revealed that for students with low level of resilience, the relationship between family functioning and academic engagement was stronger (Coeff $=.074 ; \mathrm{se}=.027 ; \mathrm{t}=2.774 ; p=.05)$ than for those with average level of resilience (Coeff
$=.049 ; \mathrm{se}=.020 ; \mathrm{t}=2.431 ; p=.05)$. However, relationship between family functioning and academic engagement was not significant for students with high level of resilience (Coeff $=.023$; $\mathrm{se}=.021 ; \mathrm{t}=1.138 ; p>.05)$. 


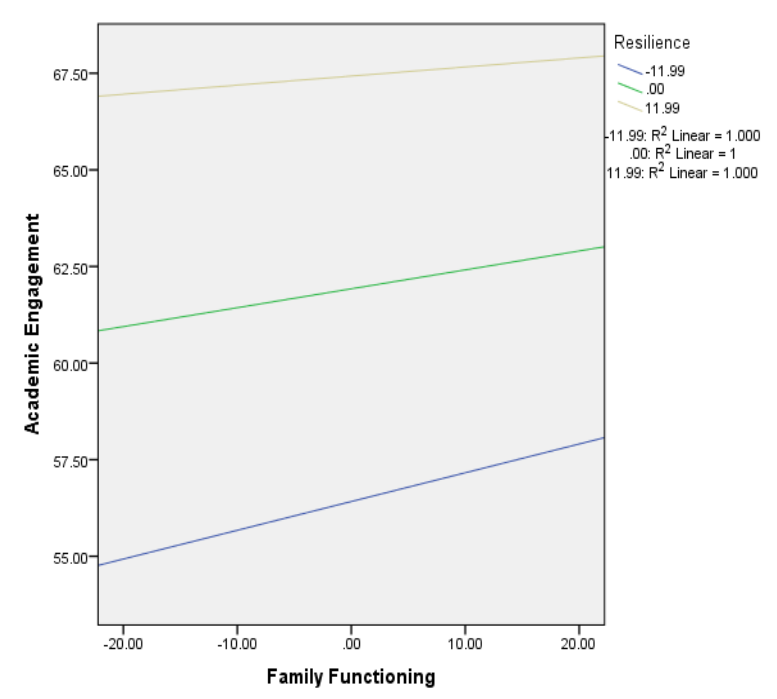

Figure 1. Chart of Moderating Role of resilience between family functioning and Academic Engagement

\section{Discussion}

This study investigated the moderating role of resilience between family functioning and academic engagement among secondary schools students in Ogun State, Nigeria.

Preliminary analysis indicated positive and significant relationships among academic engagement, family functioning and resilience. Also, resilience predicted academic engagement as hypothesisd.

Moderation analysis showed significant moderating (but inverse) effect of resilience on the relationship between family functioning and academic engagement. This was shown in the conditional effect of family functioning on academic engagement at different levels of resilience. Surprisingly, family functioning was found to predict academic engagement better when the resilience was low and average but not when resilience was high. This implies that students with low level of resilience from low functioning families would engage more in academics. This calls for a greater understanding of the mechanism by which resilience should buffer the negative effect of family functioning on academic engagement.

Findings however indicated that there is no significant effect of family functioning on academic engagement at high level of resilience. That indicates that resilience may not be required for academic engagement of students from highly functioning families.

The findings of this study whereby family functioning has been observed to affect academic engagement is not amazing as previous studies have established such directions as family functioning affects academic performance and academic performance is affected by academic engagement [52].

\section{Conclusion}

Based on the findings of this study, it was concluded that resilience significantly but negatively moderated the relationship between family functioning and academic engagement of secondary school students. This finding however calls for studies to determine the underlying mechanism in the moderating role of resilience in the relationship between family functioning and academic engagement.

\section{References}

[1] Diaz, A., Eisenberg, N., Valiente, C., VanSchyndel, S., Spinrad, T. L., Berger, R., Hernandez, M. M., Silva, K. M., \& Southworth, J. (2017). Relations of positive and negative expressivity and effortful control to kindergarteners' student-teacher relationship, academic engagement, and externalizing problems at school. Journal of Research in Personality, 3-14.

[2] Glaria, R., Carmona, L., Perez, C., \& Parra, P. (2017). Relationship among academic engagement, burnout and student perceptions of curriculum delivery in speech and language therapy students from University of Concepcion, Chile Journal of Pakistan Medical Association. 67(9), 1362-1368.

[3] Maralani, F., Mehdipour, L., Masoud, G., \& Hejazi, E. (2006). Structural modeling on the relationship between basic psychological needs, academic engagement, and test anxiety. Journal of Education and Learning, 5(4), 44-52

[4] Tian, Y., Bian, Y., Han, P., Gao, F., \& Wang, P. (2017). Class collective efficacy and class size as moderators of the relationship between junior middle school students' externalizing behavior and academic engagement: A multilevel study. Frontiers in Psychology. 18(8), 1219.

[5] Hughes, K., Coplan, R. J., \& Robert, J. (2010). Exploring processes linking shyness and academic achievement in childhood. School Psychology Quarterly, 25(4), 213-222.

[6] Strati, A. D., Schmidt, J. A., \& Maier, K. S. (2017). Perceived challenge, teacher support, and teacher obstruction as predictors of student engagement. Journal of Educational Psychology, 109(1), 131-147.

[7] Zee, M., de Jong, P. F., \& Koomen, H. M. Y. (2016). Teachers' self-efficacy in relation to individual students with a variety of social-emotional behaviors: A multilevel investigation. Journal of Educational Psychology, 108(7), 1013-1027.

[8] Maralani, F. M., Lavasani, M. G., \& Hejazi, E. (2016). Structural modeling on the relationship between basic 
psychological needs, academic engagement, and test anxiety. Journal of Education and Learning, 5(4), 44-52.

[9]Amutio, A. (2016). Emotional creativity as predictor of intrinsic motivation and academic engagement in university students: The mediating role of positive emotions. Frontiers in Psychology. 7 http://dx.doi.10.3389/fpsyg.2016.01243.

[10] Nwosu, K. C., Okwuduba, E., \& Okoye, O. (2018) Coping strategies and academic engagement of part-time undergraduate student teachers in Nigeria. Social Sciences and Education Research Review. 5(1),72-94.

[11] Sadoughi, M. (2019). Canonical correlation between psychological capital and academic engagement among students of medical sciences. Journal of Development Strategies in Medical Education 6(2), 87-101.

[12] Cornell, D., Shukla, K., \& Konold, T. R. (2016) Authoritative school climate and student academic engagement, grades, and aspirations in middle and high schools. AERA Open. 2. http://dx.doi $10.1177 / 2332858416633184$

[13] Winek, J. K. (2010). Systemic family therapy: From theory of practice. Los Angeles, CA: Sage.

[14] Mulic, M., Ferković, V., Kurtić, A., \& Pašić, I. F. (2017). Tobacco, alcohol, drugs consumption, and perception about the family functioning among adolescents in Tuzla Canton. Journal of Health Sciences, 7(3) http://dx.doi.10.17532/jhsci.2017.462.

[15] Rezaei-Dehaghani, A., Paki, S., \& Keshvari, M (2015). The relationship between family functioning and self-esteem in female high school students of Isfahan, Iran, in 2013-2014. Iranian Journal of Nursing and Midwifery Research. 20(3), 371-377.

[16] Kapke, T. L., Grace, M. A., Gerdes, A. C., \& Lawton, K. E. (2017). Latino early adolescent mental health: Examining the impact of family functioning, familism, and global self-worth. Journal of Latina/o Psychology, 5(1), 27-44. http://dx.doi.org/10.1037/lat0000057.

[17] Rezaei-Dehaghani, A., Keshvari, M., Paki, S. (2018) The relationship between family functioning and academic achievement in female high school students of Isfahan, Iran, in 2013-2014 Iranian Journal of Nursing and Midwifery $\quad$ Research. 23(3), 183-187. http://dx.doi.10.4103/ijnmr.IJNMR_87_17.

[18] Córdova, D., Heinze, J. E., Mistry, R., Salas-Wright C. P., \& Zimmerman, M. A. (2016). Ecodevelopmental trajectories of family functioning: Links with HIV/STI risk behaviors and STI among Black adolescents. Developmental Psychology, 52(7), 1115-1127. http://dx.doi.org/10.1037/dev0000136.

[19] Cano, M. Á., Schwartz, S. J., Castillo, L. G., Unger J., B., Huang, S., Zamboanga, B. L. ... \& Szapocznik, J. (2016). Health risk behaviors and depressive symptoms among Hispanic adolescents: Examining acculturation discrepancies and family functioning. Journal of Family Psychology, 30(2), 254-265. http://dx.doi.org/10.1037/fam0000142.

[20] Yahyaee, G. A., Nooranipoor, R., Shafiabadi, A., \& Farzad, V. (2015). The effectiveness of transactional analysis group-counseling on the improvement of couples' family functioning Archives of Hygiene Sciences. 4(2), 73-79.

[21] Ghamari M. (2011). The comparison of family functioning dimensions and quality of life and their relationships among addicted and non-addicted persons. Research on Addiction. 5(18), 55-68.

[22] Dabaghi, S., Sheikholeslami, F., Chehrzad, M. M., Leyli, E. K. N. (2018). Relationship between family functioning and aggression in high school students. Journal of Holistic Nursing and Midwifery. 28(1), 35-43.

[23] Organisation for Economic Cooperation and Development (OECD, 2005).

[24] Jongen, C., Langham, E., Bainbridge, R., \& McCalman, J. (2019). Instruments for measuring the resilience of indigenous adolescents: An exploratory review. Frontiers in Public Health. 7 http://dx.doi.10.3389/fpubh.2019.00194.

[25] Greenberg, J. M., Wynn, J. K., Lee, J., Hellemann, G., Gabrielian, S., \& Green, M. F. (2018). Resilience in homeless veterans: clinical and cognitive correlates. Psychiatric Rehabilitation Journal, Nov 29, No Pagination Specified.

[26] Sætren, S. S., Sætren, S. S., Sütterlin, S., Sütterlin, S., Lugo, R. G., Prince-Embury, S., \& Makransky, G. (2019). A multilevel investigation of resiliency scales for children and adolescents: the relationships between self-perceived emotion regulation, vagally mediated heart rate variability, and personal factors associated with resilience. Frontiers in Psychology. 10 http://dx.doi.10.3389/fpsyg.2019.00438.

[27] Bruneau, M., Chang, S. E., Eguchi, R. T., Lee, G. C., O'Rourke, T. D., Reinhotn, A. M., Shinouzuka, M., Tierney, K., \& Wallance, W. A. (2013). A framework to quantitatively assess and enhance the seismic resilience of communities. Earthquake Spectra, 20, 739-755.

[28] Fougere, A., \& Daffern, M. (2011). Resilience in youth offenders. International Journal of Forensic Mental Health, 10, 244-253.

[29] Jacelon, C. S. (1997). The trait and process of resilience. Journal of Advanced Nursing, 25(1), 123-129.

[30] Richardson, G. E. (2002). The metatheory of resilience and resiliency. Journal of Clinical Psychology, 58(3), 307-321.

[31] Kaye-Tzadok, A., \& Davidson-Arad, B. (2016). Posttraumatic growth among women survivors of childhood sexual abuse: Its relation to cognitive strategies, posttraumatic symptoms, and resilience. Psychological Trauma: Theory, Research, Practice, and Policy, 8(5), 550558. 
[32] Albuquerque, S., Narciso, I., \& Pereira, M. (2018). Posttraumatic growth in bereaved parents: A multidimensional model of associated factors. Psychological Trauma: Theory, Research, Practice, and Policy, 10(2), 199-207.

[33] Watson, L. B., Morgan, S. K., \& Craney, R. (2018). Bisexual women's discrimination and mental health outcomes: The roles of resilience and collective action. Psychology of Sexual Orientation and Gender Diversity, 5(2), 182-193.

[34] Forbes, S., \& Fikretoglu, D. (2018). Building resilience: The conceptual basis and research evidence for resilience training programs. Review of General Psychology, 22(4), 452-468.

[35] Zhang, Y., Zhang, Y., Zhang, X., Zhang, L., Guo, C., \& Guo, C. (2019). Executive function and resilience as mediators of adolescents' perceived stressful life events and school adjustment. Frontiers in Psychology. 10 http://dx.doi.10.3389/fpsyg.2019.00446.

[36] Mestre, J. M., Núñez-Lozano, J. M., GómezMolinero, R., Zayas, A., \& Guil, R. (2017). Emotion regulation ability and resilience in a sample of adolescents from a suburban area. Frontiers in Psychology, 8 http://dx.doi. 10.3389/fpsyg.2017.01980.

[37] Lee, H. H., \& Cranford, J. A. (2008). Does resilience moderate the associations between parental problem drinking and adolescents' internalizing and externalizing behaviors? A study of Korean adolescents. Drug and Alcohol Dependence, 96(30), 213-221.

[38] Pinquart, M. (2009). Moderating effects of dispositional resilience on associations between hassles and psychological distress. Journal of Applied Developmental Psychology, 30(1), 53-60.

[39] Kong, L., Liu, Y., Li, G., Fang, Y., \& Li, P. (2016) Resilience moderates the relationship between emotional intelligence and clinical communication ability among Chinese practice nursing students: A structural equation model analysis. Nurse Education Today, 46, 64-68.

[40] Zahradnik, M., Stewart, S. H., O'Connor, R. M., Stevens, D., Ungar, M., \& Wekerle, C. (2010). Resilience moderates the relationship between exposure to violence and posttraumatic reexperiencing in Mi'kmaq youth. International Journal of Mental Health and Addiction, 8(2), 408-420.

[41] Niu, G., Sun, X., Tian, Y., Fan, C., \& Zhou, Z. (2016). Resilience moderates the relationship between ostracism and depression among Chinese adolescents. Personality and Individual Differences, 99, 77-80.

[42] García-Izquierdo, M., Ríos-Risquez, M. L., CarrilloGarcía, C., \& Sabuco-Tebar, E. (2018). The moderating role of resilience in the relationship between academic burnout and the perception of psychological health in nursing students. Educational Psychology, 2018, 38(8), 1068-1079.
[43] Thurston, I. B., Hardin, R., Kamody, R. C., Herbozo, S. \& Kaufman, C. (2018). The moderating role of resilience on the relationship between perceived stress and binge eating symptoms among young adult women. Eating Behaviors, 29, 114-119.

[44] Ying, L., Wang, Y., Lin, C., \& Chen, C. (2016a). Trait resilience moderates the longitudinal linkage between adolescent Posttraumatic Stress Disorder Symptoms and Posttraumatic Growth. School Psychology International, 37(3), 207-222.

[45] Ying, L., Wang, Y., Lin, C., \& Chen, C. (2016b). Trait resilience moderated the relationships between ptg and adolescent academic burnout in a Post-disaster Context. Personality and Individual Differences, 90, 108112

[46] Creswell, J. W. (2003). Research design: Qualitative, quantitative and mixed methods approaches (2nd edition). Thousand Oaks, California, USA: Sage.

[47] Schaufeli, W. B., Martínez, I. M., Pinto, A. M., Salanova, M., \& Bakker, A. B. (2002). Burnout and engagement in university students: A crossnational study. Journal of Cross-cultural Psychology, 33(5), 464-481.

[48] Schaufeli, W. B., Salanova, M., González-Romá, V., $\&$ Bakker, A. B. (2002). The measurement of engagement and burnout: A two-sample confirmatory factor analytic approach. Journal of Happiness Studies, 3(1), 71-92. http://dx.doi.10.1023/A:1015630930326.

[49] Neabel, B., Fothergill-Bourbonnais, F., \& Dunning, J. (2000). Family assessment tools: A review of the literature from 1978-1997. Heart and Lung: The Journal of Acute and Critical Care 29(3);196-209.http://dx.doi.10.1067/ mhl.2000.106938.

[50] Connor, K. M., \& Davidson, J. R. T. (2011). Development of a New Resilience Scale: The ConnorDavidson Resilience Scale (CD-RISC). Depress Anxiety, 18(2), 76-82.

[51] Hayes, A. F. (2013). Introduction to mediation, moderation and conditional process analysis: A regressionbased approach. New York: The Gilford Press.

[52] Zolkoski, S. M. \& Bullock, L. M. (2012). Resilience in children and youth: A review. Children and Youth Services Review, 34 (12), 2295-2303. 